REVISTA BRASILEIRA DE ZOOLOGIA

Revista brasileira de Zoologia, S. Paulo 3(7): 433-440

31. V.1987

\title{
RECONHECIMENTO DO GRUPO rizibilis; DESCRIÇÃO DE UMA NOVA ESPÉCIE DE Hyla (AMPHIBIA, ANURA)
}

GILDA V. ANDRADE 1,2 ADĀO J. CARDOSO 2

\section{ABSTRACT}

Hyla ranki, sp. $n$. , is described from the state of Minas Gerais, southeastern Brazil. This new species resembles Hyla rizibilis Bokermann, 1964. The advertising call and the tadpole are also described. Observations on the biology of the new species are referred and the recognition of the group rizibilis, constituted by $\boldsymbol{H}$. rizibilis and $\boldsymbol{H}$. ranki, sp. $n$., is proposed. Hyla mirim B. Lutz, 1972 is synonymized with $H$. rizibilis.

No complexo catharinae, reconhecido por B. Lutz (1973), Hyla rizibilis Bokermann, 1964 e Hyla mirim B. Lutz, 1972 foram consideradas como um grupo à parte, aparentado às espécies com manchas amarelas nos flancos. Trabalhando em serras no sul do Estado de Minas Gerais, encontramos uma espécie com caracterís ticas semelhantes às de $\mathbf{H}$. rizibilis e $\mathbf{H}_{\text {. }}$ mirim, o que nos levou a visitar as localida des-tipo destas espécies, para esclarecimento da sua taxonomia.

Em Rio Vermelho, localidade-tipo de $\mathbf{H}$. mirim, realizamos coletas com o $\mathrm{Sr}$. Abllio Rank, filho de F. Rank, coletor da

série-tipo de H.. mirim, e aí coletamos um exemplar (ZUEC 5290) com características fornecidas na descrição desta espécie. Em Corupá (antiga Humboldt), localizada ao sul de Rio Vermelho, observamos, gravamos e coletamos diversos exemplares de $\mathbf{H}$. rizibilis. Estas gravações foram comparadas e se mostraram semelhantes às efetuadas por Bokermann e utilizadas na caracterização de $\mathbf{H}$. rizibilis.

Como já havia sido referido por B. Lutz (1973), exemplares da série tipo de $\mathbf{H}$. mirim estavam bastante mal fixados, o que dificulta sua caracterização: as medidas foram prejudicadas pela postura arqueada dos exemplares e má fixação. Por outro lado, a mancha "diagnóstica", clara e alongada com barras transversais, foi referida também por Bokermann (1964) na descrição de $\mathbf{H}$. rizibilis. Assim, estas caracte rísticas, utilizadas na diagnose de $\mathbf{H}$. mirim não justificavam a proposição de uma

1. Bolsista da FAPESP (Proc..81/0510-6).

2. Departamento de Zoologia, Universidade Estadual de Campinas, CEP 13100; Campinas, Såo Paulo, Br. 


\section{Revista brasileira de Zoologia}

nova espécie, especialmente naquelas condiçôes dos exemplares-tipo. Além disso, o nosso achado de $\mathbf{H}$. rizibilis em Corupá invalida o proposto por B. Lutz (1973) de que $\mathbf{H}$. mirim seria uma forma meridional próxima a $\mathbf{H}$. rizibilis. Pelos motivos expostos, consideramos Hyla mirim B. Lutz como sinónimo júnior de Hyla rizibilis Bokermann.

Uma característica importante de $\mathbf{H}_{\text {. }}$ rizibilis é a posição e a forma do saco vocal; constatamos, no exemplar WCAB 13940, que ele é contínuo e exíguo na região subgular, porém bastante expandido lateralmente. Sugerimos aqui que esta característica, singular no complexo catharinae "sensu" B. Lutz (1973), seja considerada para o reconhecimento do grupo rizibilis, que seria constituído por $\mathbf{H}$. rizibilis e pela nova espécie que descrevemos a seguir.

Abreviaturas usadas para identificaçăo dos espécimes aqui referidos: ZUEC (Departamento de Zoologia, Universal Estadual de Campinas); MZUSP (Museu de Zoologia, Universidade de São Paulo) e WCAB (Coleção Werner C.A. Bokermann, São Paulo). As medidas são dadas em milímetros.

As vocalizaçóes foram gravadas em aparelho UHER 4000 IC, a $19 \mathrm{~cm} / \mathrm{s}$ e os sonogramas foram analisados em aparelho Sound Spectrograph, série 700 da Voice Identification Inc., com filtro "wide".

\section{Hyla ranki, $s p . n$}

Diagnose - Espécie de porte pequeno (o 20 - $23 \mathrm{~mm}$ ); saco vocal lateral subgular; calosidades bem marcadas; membros posteriores e antebraços com barras dorsais escuras; mancha interocular triangular, com ápice voltado para trás; partes ocultas da coxa e região inguinal creme-esverdeadas.

Holótipo - MZUSP 59540, macho adulto, proveniente do Morro do Ferro, Mun. Poços de Caldas, Minas Gerais, Brasil (2 $21^{\circ} 52^{\prime} \mathrm{S}, 46^{\circ} 50^{\prime} \mathrm{W}$; aprox. $1400 \mathrm{~m}$ alt.), coletado em 01 de agosto de 1980 por Adão J. Cardoso, Célio F. B. Haddad e Gilda V. Andrade.

Parátipos - Todos coletados no mesmo local que o holótipo. Machos adultos: ZUEC 5400-5406 e MZUSP 59541-59542, coletados na mesma ocasião que o hoIótipo; ZUEC 4490, coletado a 15 de novembro de 1981 pelos mesmos coletores; WCAB 48147 - 48149, coletados a 02 de julho de 1981, pelos mesmos coletores; ZUEC 4535, coletado a 13 de dezembro de 1981 por A.J. Cardoso e G.V. Andrade; ZUEC 5027-5032, coletados a 17 de julho de 1982 por A.J. Cardoso e G.V. Andrade; MZUSP 59543, 59545 E 59546, coletados a 22 de março de 1980 por A.J. Cardoso, C.F.B. Haddad, Gilberto O. Aguiar, G. V. Andrade e Cristina P. Sandoval. Fêmeas adultas: ZUEC 4309-4310, coletadas a $7 / 8$ de janeiro de 1981 por A.J. Cardoso, C.F.B. Haddad, e G.V. Andrade; MZUSP 59544, coletada a 22 de março de 1980 por A.J. Cardoso, C.F.B.Haddad, G.O.Aguiar, G.V.Andrade e C.P.Sandoval.

Descrição do holótipo - Porte esbelto (Fig. 5); comprimento da cabeça $(8,5)$ pouco maior que $1 / 3$ do comprimento total $(22,0)$. Focinho arredondado, levemente truncado, quando visto de perfil (Fig. 1) e arredondado quando visto de cima (Fig. 2). Narinas salientes, próximas à extremidade do focinho. Regiáo loreal côncava; canto rostral pouco evidente. Olhos salientes, com o seu diâmetro $(2,4)$ próximo de $2 / 3$ do espaço interocular $(1,8)$. Timpano circular, com metade do diámetro ocular; prega supratimpânica evidente. Saco vocal lateral e subgular. Dentes vomerianos em duas séries um pouco separadas, entre as coanas, que têm forma eliptica. Língua livre nos bordos posteriores. Membrana pouco desenvolvida entre os dedos; discos adesivos de tamanho variado, bem menores que o tímpano (Fig. 3). Um calo 
Vol. 3(7), 1987

1

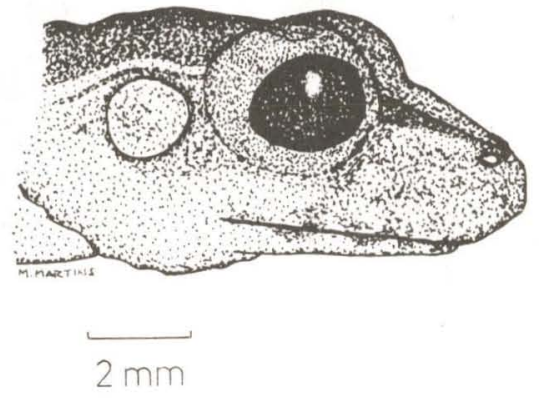

3

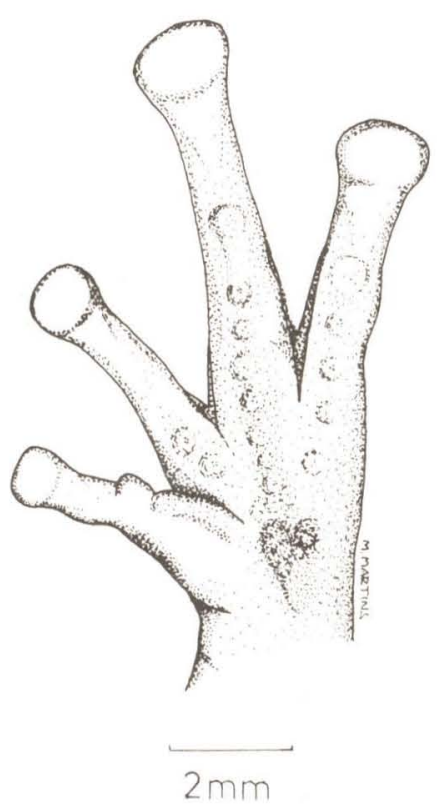

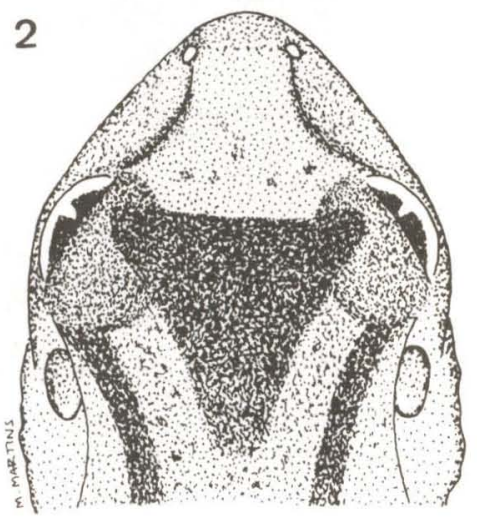

4

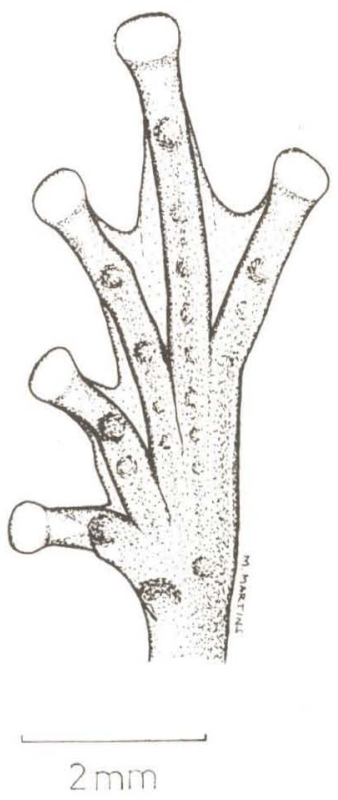

Figs. 1 - 4 Hyla ranki, sp. n. (MZUSP 59540) - cabeça em vista de perfil e dorsal; mão e pé em vista ventral. 


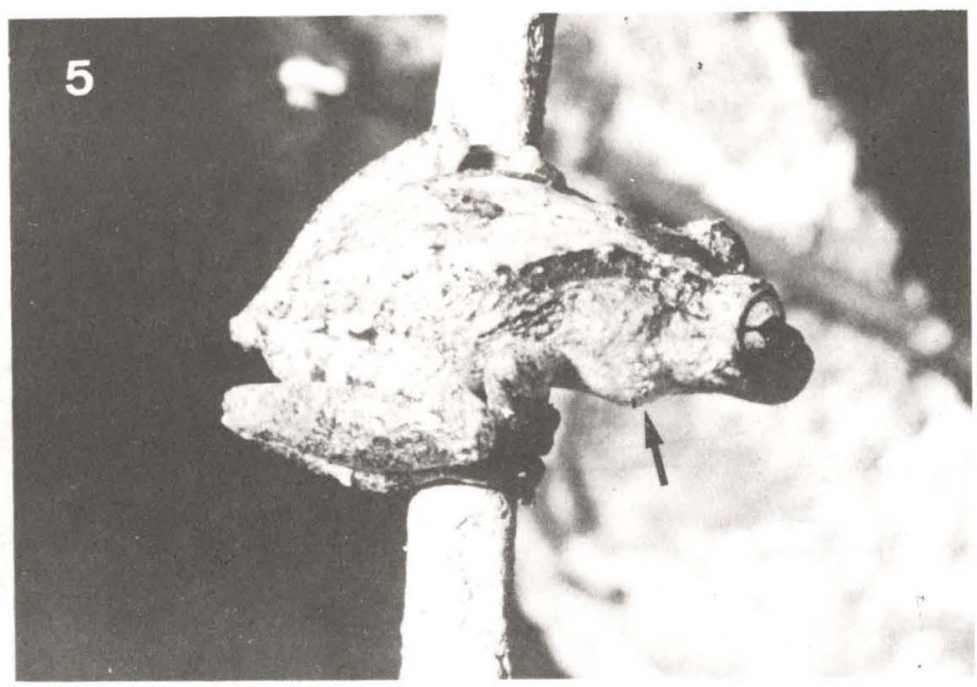

$\mathrm{kHz}$

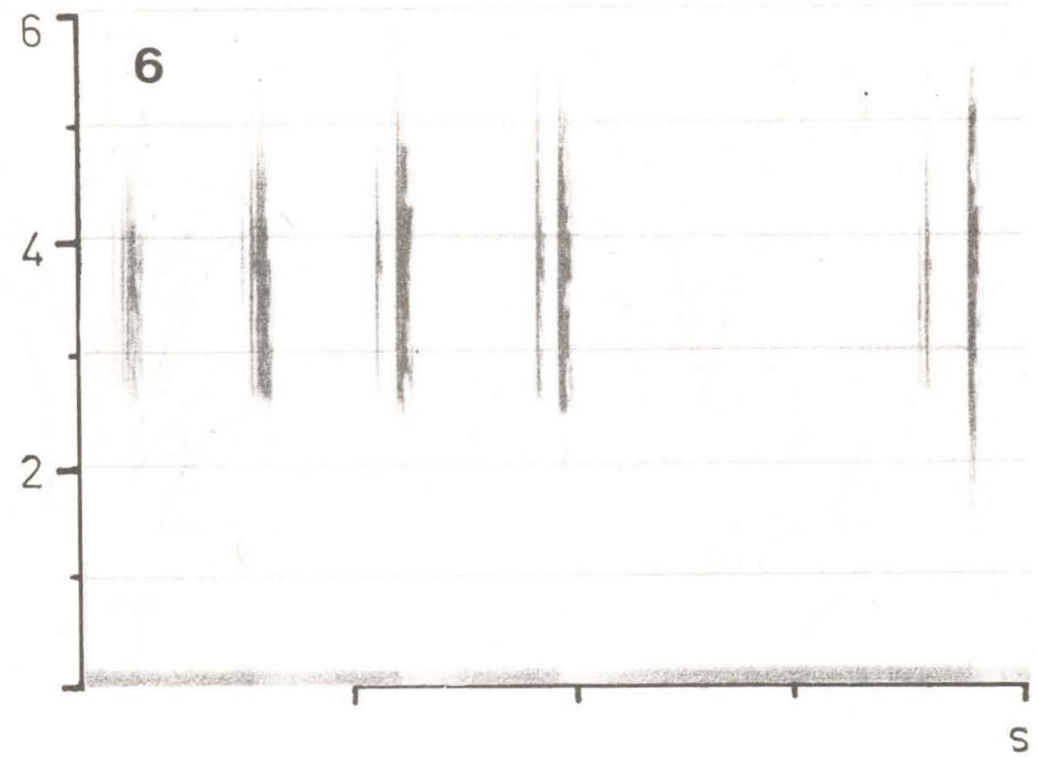

Fig. 5 - Hyla ranki, sp. n., macho. Comprimento total aproximado de $22 \mathrm{~mm}$. A seta indica o saco vocal lateral e subgular. Fig. 6 - Hyla ranki, sp. n. sonograma da vocalizaçăo, Morro do Ferro, Mun. Poços de Caldas, MG, $01 \mathrm{de}$ agosto de $1980,20: 00 \mathrm{~h}$, temp. ar $14^{\circ} \mathrm{C}$, temp. água $18^{\circ} \mathrm{C}$. Faixa de análise $300 \mathrm{~Hz}$. Controle de gravação AJC 03/03. 

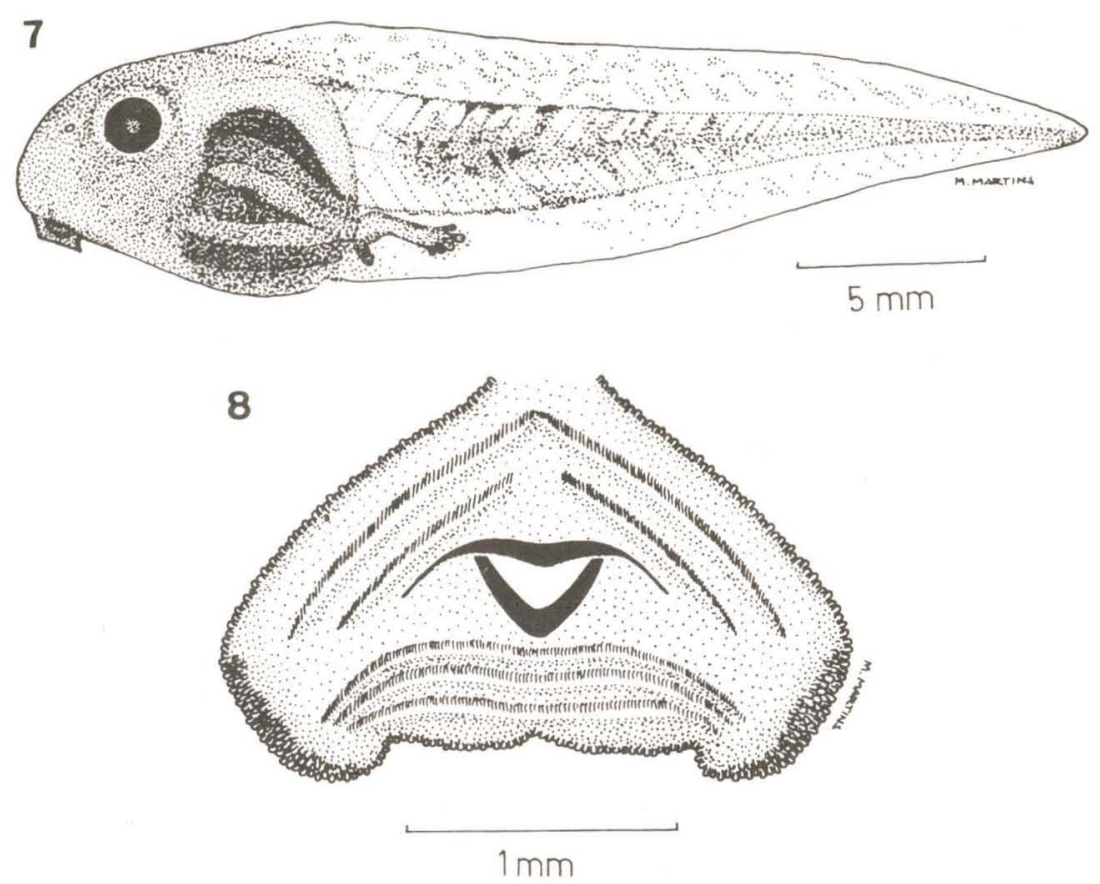

\section{8}

Fig. 7 - 8 Girino de Hyla ranki, sp. n. - vista lateral e boca em vista frontal.

subarticular bem desenvolvido nos dedos; fileira de pequenas calosidades ao longo dos dedos 3 e 4; prepólex ausente; calos metacarpais bem desenvolvidos. Comprimento do fêmur $(11,3)$ e da tíbia $(11,7)$ juntos, semelhante ao do corpo. Tamanho dos discos dos artelhos ao do $2^{\circ}$ dedo (Fig. 4). A membrana interdigital atinge aproximadamente $2 / 3$ entre os dedos $2^{\circ}-3 \circ, 3^{\circ}-44^{\circ}$ e $4^{\circ}-5^{\circ}$ e é menor entre os $1 \%-2^{\circ}$. Calos subarticulares bem desenvolvidos, com pequenas calosidades intercaladas; calos metatarsais externo e interno bem evidentes. Prega dérmica lateral pouco evidente, ao longo do pé; calcanhar com pequenos tubérculos. Pele da porçăo ventral granulosa; dorso e flancos levemente granulosos, ressaltando alguns tubérculos irregularmente distribuifos principalmente na cabeça e nas porções dorsolaterais.

No exemplar vivo, a coloração dorsal é castanha; mancha interocular triangular, com ápice voltado para trás. Essa mancha é castanho escura e persiste também nos exemplares fixados; linhas escuras dorso-laterais estendem-se de cada olho até a região sacral, delimitando uma área mais clara em forma de $Y$, que se estende até pouco mais que a metade do corpo, onde torna-se difusa. Na regiāo dorsal dos membros existem barras transversais castanho escuras, havendo $4 \mathrm{na}$ coxa, 3 na tíbia, 3 no pé e 2 no antebraço. A regiảo ventral é clara, com pontuaçōes escuras, principalmente nos membros e região gular. As partes ocultas da coxa e a 
Tabela 1.

\begin{tabular}{|c|c|c|c|c|c|c|c|c|c|c|c|c|}
\hline Exemplar $n^{\circ}$ & $\begin{array}{l}\text { ZUEC } \\
4309\end{array}$ & $\begin{array}{l}\text { ZUEC } \\
4310\end{array}$ & $\begin{array}{l}\text { ZUEC } \\
5400\end{array}$ & $\begin{array}{l}\text { ZUEC } \\
5401\end{array}$ & $\begin{array}{l}\text { ZUEC } \\
5402\end{array}$ & $\begin{array}{l}\text { ZUEC } \\
5403\end{array}$ & $\begin{array}{l}\text { ZUEC } \\
5404\end{array}$ & $\begin{array}{l}\text { ZUEC } \\
5405\end{array}$ & $\begin{array}{l}\text { MZUSP } \\
59544\end{array}$ & $\begin{array}{l}\text { MZUSP } \\
59540\end{array}$ & $\begin{array}{c}\text { MZUSP } \\
59541\end{array}$ & $\begin{array}{l}\text { MZUSP } \\
59542\end{array}$ \\
\hline Comprimento total & 27.0 & 27.3 & 21.4 & 22.3 & 22.5 & 21.4 & 22.3 & 23.0 & 28.7 & 22.0 & 23.3 & 20.2 \\
\hline Comprimento da cabeça & 10.5 & 10.5 & 8.0 & 8.3 & 8.3 & 7.9 & 8.5 & 8.3 & 10.0 & 8.5 & 8.6 & 8.0 \\
\hline Largura da cabeça , & 9.1 & 9.4 & 7.3 & 7.8 & 7.1 & 6.5 & 7.3 & 7.3 & 9.7 & 7.3 & 7.7 & 6.8 \\
\hline Diâmetro do olho & 2.7 & 3.2 & 2.8 & 2.4 & 2.3 & 2.4 & 2.5 & 2.2 & 3.0 & 2.4 & 2.8 & 2.4 \\
\hline Espaço interocular & 2.3 & 2.7 & 2.1 & 2.2 & 2.1 & 2.1 & 2.3 & 2.1 & 2.5 & 1.8 & 1.8 & 1.6 \\
\hline Distância olho-narina & 1.7 & 2.0 & 1.6 & 1.6 & 1.6 & 1.4 & 1.8 & 1.9 & 2.0 & 1.4 & 2.0 & 1.2 \\
\hline Diâmetro do tímpano & 1.0 & 1.5 & 1.3 & 1.6 & 1.0 & 1.0 & 0.9 & 0.7 & 1.4 & 1.2 & 1.4 & 1.0 \\
\hline Comprimento do fêmur & 14.0 & 14.4 & 10.1 & 11.3 & 11.1 & 10.2 & 11.4 & 11.5 & 13.3 & 11.3 & 10.9 & 9.8 \\
\hline Comprimento da tîbia & 15.0 & 14.9 & 11.2 & 12.1 & 11.6 & 11.3 & 12.0 & 11.9 & 14.6 & 11.7 & 11.7 & 10.6 \\
\hline Comprimento do pé & 20.5 & 20.0 & 15.7 & 16.6 & 16.3 & 15.0 & 16.1 & 16.5 & 20.0 & 16.2 & 15.9 & 14.6 \\
\hline
\end{tabular}

Tabela 1 - Medidas (mm) da série de lyla ranki, sp. n. O exemplar MZUSP 59540 é o holótipo. Os parátipos ZUEC $4309-4310$ e MZUSP 59544 são fêmeas; os demais são machos. 
regiāo inguinal são esverdeadas e apresentam manchas escuras. Mancha clara difusa embaixo do olho, acompanhando a borda da maxila, com pontuações escuras. Íris amarelo-dourada.

Variação - existe uma certa variação nas medidas da série-tipo (Tabela 1). O número de calosidades das mãos e dos pés, tubérculos dorsais e dorso-laterais também varia, assim como a quantidade das pontuações escuras ventrais. A coloração dorsal varia de tons bem claros a bem escuros de castanho. A mancha interocular nem sempre tem contornos regulares. O número de barras nos membros pode variar e ao longo da maxila pode haver barras escuras.

Comparação com outras espécies - Hyla ranki, sp. n., difere de H. rizibilis pelos dłscos adesivos menores, distância interocular menor, focinho mais comprido e subacuminado, diferente padrão de coloração nos indivíduos vivos; diferente estrutura de vocalização e distingue-se de Hyla berthae Barrio, 1962, pelo maior porte, constituição mais robusta, vocalizações, ausência de manchas amarelas nos flancos, saco vocal lateral e subgular.

Vocalização - as vocalizações dessa espécie são bastante variadas. O tipo de canto mais comum (Fig. 6) consiste na emissão de séries com 4 ou 5 notas curtas, sendo a primeira delas entre 2,5 e $4,5 \mathrm{kHz}$ e as demais em faixa mais ampla, entre 2,2 e 5,5 kHz; estas notas são separadas por intervalos aproximados de 0,12 s. Após esta série inicial, é emitida uma última nota entre 1,5 e $5,5 \mathrm{kHz}$ e separada da série inicial por cerca de $0,3 \mathrm{~s}$. Todas as notas são formadas por pulsos transitórios, em geral sobrepostos. As variaçōes verificadas provavelmente são decorrentes de diferentes funções que as vocalizações podem desempenhar, como ocorre em diversas outras espécies (Cardoso, 1981).

Girinos - Um girino no estágio 37 de desenvolvimento, da tabela de Gosner (1960), tem $28,7 \mathrm{~mm}$ de comprimento. Visto de cima, o corpo $(10,4)$ é oval e com a ponta do focinho romba; visto de perfil (Fig. 7), tem forma ovóide. Narinas laterais, situadas superiormente na porção posterior da cabeça. Olhos laterais, sendo a distância entre ele de 2 a 2,5 vezes o diâmetro do olho. Espiráculo pouco abaixo da linha mediana, na metade posterior do lado esquerdo do corpo, formando um tubo externo curto. Altura máxima da cauda pouco maior que a altura máxima do corpo. Nadadeira superior pouco mais larga que a inferior e, em diversos exemplares, mais alta na área de emersão do corpo. Forma da cauda lanceolada, terminando em ponta pouco afilada. Boca (fig. 8) ventral, com lábios desenvolvidos circundados por papilas, exceto na regiâo mediana do lábio superior; papilas de tamanhos semelhantes e extremidades rombas. No lábio superior há duas fileiras de dentículos córneos, sendo a externa contínua e a interna interrompida na região mediana. Lábio inferior com três fileiras de dentículos córneos, todas contínuas. Bico córneo forte e discretamente denteado na peça superior. Em vida, a coloração do corpo é uniforme, de cor castanha, tendo a região anterior dorsal tons mais claros, amarelados, e a região ventral, sobre o intestino, tons escuros, acastanhados. Cauda transparente, com tons castanho-amarelados e pontuações escuras pouco perceptíveis. Região musculosa da cauda delimitada por linha castanho-escura, com 2 estrias, também neste tom, longitudinalmente, dividindo-a em 3 regiōes aproximadamente iguais. Íris amarela, com tons acobreados. No formol, as linhas que delimitam a porção musculosa da cauda, bem como as estrias longitudinais, vão desaparecendo com o tempo e a íris torna-se escura.

Biologia - Machos de Hyla ranki, sp. n., foram encontrados em pequenas matas ciliares, iniciando a emissão das vocalizações logo após o ocaso. Os sítios de canto estavam situados geralmente sobre pteridófitas, mas também em gramineas, numa altura variável entre 0,2 e $1,0 \mathrm{~m}$, estando essa vegetaçăo à beira de 
riachos ou de poças de água parada ou renovada. Durante o dia, diversos indivíduos foram encontrados no interior de bromélias epífitas. As larvas foram encontradas em poças de água renovada, principalmente, ou parada, de fundo argiloso, entre detritos, ou nas margens de riachos, onde se formam poças com água de pouca correnteza e maior acúmulo de matéria orgánica.

Etimologia - O epiteto especifico é dado em homenagem ao Sr Abílio Rank, que tem contribuído para o estudo de biologia de anfíbios na região de São Bento do Sul, SC

Considerando o grupo rizibilis, concordamos com B Lutz (1973) sobre a possibilidade de $\mathbf{H}$. berthae ser espécie composta; isto nos parece bastante provável em vista de esta espécie não mais ter sido encontrada em São Bernardo do Campo e os parátipos (LIH 1088-1089), referidos por Barrio (1962) como dal procedentes, seriam de fato exemplares deH. rizibilis. Porém, uma definição segura só será pos. sivel após o exame dos parátipos acima referidos.

Fouguette \& Delahousaye (1977) propuseram o reconhecimento do gênero Ololygon Fitz., que foi adotado por alguns autores Porém este procedimento năo tem sido seguido na literatura brasileira, tendo em vista os motivos já discutidos em trabalhos anteriores (Cardoso \& Sazima, 1980; Cruz \& Peixoto, 1982; Cardoso e Haddad, 1982)

\section{AGRADECIMENTOS}

A Dr. Ivan Sazima, pela orientação, leitura do manuscrito e sugestões; Dr. Jacques Vielliard, pela confecção do sonograma e sugestóes; Prof. Werner C.A Bokermann pelo empréstimo de parátipos de $\mathbf{H}$. rizibilis; Márcio $\mathrm{C}$. Martins, pelos desenhos; Célio F.B. Haddad, pelo auxilio nos trabalhos de campo; FAPESP, pelo auxílio concedido.

\section{REFERÊNCIAS}

BARRIO, A., 1962. Los Hylidae de Punta Lara, Provincia de Buenos Aires Physis $23(65) ; 129-142$.

BOHERMANN, W.C.A., 1964. Uma nova espécie de Hyla da Serra do Mar em São Paulo. Rev. Brasil. Biol. 24(4): 429-434.

CARDOSO, A.J., 1981. Organizaçáo espacional e temporal na reproduçáo e vida larvária em uma comunidade de hilideos no sudeste do Brasil (Amphibia, Anura). Campinas. Dissertaçăo de Mestrado, Universidade Estadual de Campinas.

CARDOSO, A.J. \& SAZIMA, I., 1980. Nova espécie de Hyla do sudeste brasileiro (Amphibia, Anura, Hylidae). Rev. Brasil. Biol. 40(1): 75-79

CARDOSO, A J. \& HADDAD, C.F B., 1982. Nova espécie de Hyla da Serra da Canastra (Amphibia, Anura, Hylidae). Rev. Brasil. Biol. 42(3): 499-503.

CRUZ, C.A.G. \& PEIXOTO, O.L., 1982. Uma nova espécie de Hyla do Estado do Espírito Santo, Brasil (Amphibia, Anura, Hylidae). Rev. Brasil. Biol. 42(4): $721-724$.

FOQUETTE Jr., M.J. \& DELAHOUSSAYE, A.J., 1977. Sperm morphology in the Hyla rubra group (Amphibia, Anura, Hylidae), and its bearing on generic status. J. Herpetol 11(4): 387-396

GOSNER, K.L., 1960. A simplified table for staging anuran embryos and larvae with notes on identification. Herpetologica, 16: 183-190

LUTZ, B., 1973. Brazilian species of Hyla Üniv. Texas Press, Austin \& London. $X V I I I+260 p p$. 